\title{
Bringing inclusivity to robotics with INBOTS
}

To the Editor - Advances in robotics and digital transformation currently make it possible to move robotic systems beyond the factory assembly line into private and institutional spaces such as our homes, schools and hospitals. In these places, robotics can facilitate human-machine cooperation and achieve what would not be possible for a human being or a machine separately. For example, self-driving cars use data from thousands of human drivers to learn how to respond appropriately, and robotic surgical systems enable surgeons to perform minimally invasive operations. The benefits may be substantial but it will be necessary to ensure that these are fairly distributed. We believe that current developments in robotics and the majority of existing robo-ethical reflections ${ }^{1}$ do not sufficiently consider the paradigm of inclusivity. Inclusive robotics requires an ethical design approach that guarantees security, accessibility and respect for human dignity.

The implementation of inclusive robotics can only happen with international support. We are participating in a Horizon 2020 project, financed by the European Commission, called INBOTS, which promotes inclusive robotics. The overall objective of INBOTS is to create a strong community hub, bringing together experts who can share experiences and debate various issues around responsible research, technology transfer, regulation and legislation. The INBOTS programme expects to help increase adoption of interactive robotics by end-users, improve understanding of societal needs by researchers from industry and academia, and create an adequate regulatory framework.

Inclusive robotics should aspire to be a robotics of the people, by the people and for the people. This involves the consideration of a range of ethical, political and policy issues regarding autonomy, dependence, vulnerability, functioning, care and disability. Guidelines may be found in legislative frameworks, such as the Convention on the Rights of the Child ${ }^{2}$ and the Convention on the Rights of Persons with Disabilities $^{3}$, and normative frameworks ${ }^{4}$, which promote the rights of all humans of different capabilities.

Inclusive robots should have two basic properties: (i) they must be easy to use artefacts and (ii) they must contribute to making accessibility easier in distinct environments (for example, educational, health and labour environments). In other words, robots or assistive technologies should be designed to understand as well as anticipate user needs. The INBOTS research agenda has proposed benchmarking ${ }^{5}$ as an important instrument to evaluate the 'technology readiness level' and quantify how robotic solutions satisfy the needs of potential users (http://eurobench2020. $\mathrm{eu}$ ). In this sense, benchmarking is an instrument for creating robots adapted to the diverse functional characteristics of people.

Inclusive robotics can only be achieved if the robotics industry and its researchers establish unconventional collaborations with researchers from other disciplines, such as philosophers, lawyers, sociologists, anthropologists, medical experts and economists. We believe that the process of bringing inclusivity to robotics will situate the field as an important contributor to the construction of a fairer society.

\section{Aníbal Monasterio Astobizat,2* Mario Toboso 3 , Manuel Aparicio ${ }^{4}$, Txetxu Ausín ${ }^{5}$, Daniel López ${ }^{5}$, Ricardo Morte ${ }^{6}$ and José Luis Pons ${ }^{7}$} ${ }^{1}$ Institute for Logic, Cognition, Language, and Information, University of the Basque Country, Bilbao, Spain. ${ }^{2}$ Center for Bioethics, Harvard University, Cambridge, MA, USA. ${ }^{3}$ Department of Science, Technology and Society, Institute of Philosophy, Spanish National Research Council (CSIC), Madrid, Spain. ${ }^{4}$ University of Murcia, Murcia, Spain. ${ }^{5}$ Department of Theoretical and Practical Philosophy, Institute of Philosophy, Spanish National Research Council (CSIC), Madrid, Spain. ${ }^{6}$ University of Granada, Granada, Spain. ${ }^{7}$ Neural Rehabilitation Group, Cajal Institute, Spanish National Research Council (CSIC), Madrid, Spain. *e-mail:anibal.monasterio@ehu.eus

Published online: 8 April 2019 https://doi.org/10.1038/s42256-019-0040-5

\section{References}

1. Report of COMEST on Robotics Ethics (UNESCO, 2017); http:// unesdoc.unesco.org/images/0025/002539/253952E.pdf

2. Convention on the Rights of the Child (UN, 1989); http://www. refworld.org/docid/3ae6b38fo.html

3. Convention on the Rights of Persons with Disabilities (UN, 2007); http://www.refworld.org/docid/45f973632.html

4. Nussbaum, M. C. \& Sen, A. (eds) The Quality of Life (Oxford Univ. Press, 1993).

5. Strategic Research Agenda for Robotics in Europe 2014-2020 962-993 (euRobotics, 2014); https://www.eu-robotics. net/cms/upload/topic_groups/SRA2020_SPARC.pdf

The authors declare no competing interests. 